\title{
The impact of empathy and perspective-taking instructions on proponents and opponents of immigration
}

\author{
Olga M. Klimecki (iD ${ }^{1,2,3,4 凶}$, Matthieu Vétois ${ }^{1,5}$ \& David Sander (1) ${ }^{1,6}$
}

In many societies, immigration is a conflictual topic, leading to heated exchanges between proponents and opponents of immigration. Such debates on immigration might benefit from the engagement of the discussants in empathy and perspective taking. Although empathy and perspective-taking exercises can be beneficial in some contexts, previous research shows marked differences in people with a rightist versus a leftist political orientation when it comes to their motivation to engage in empathy. The degree to which this applies to perspective taking and to the context of debates on immigration has not yet been tested. The current study, conducted in Switzerland, tested how proponents or opponents of immigration react to instructions for empathy and perspective taking in debates on immigration. The results reveal that, compared with participants in the control condition who had no instructions, proponents of immigration who received instructions were more motivated or willing to engage in empathy and perspective taking. Furthermore, proponents of immigration showed decreases in their positive and negative emotions under the perspective-taking instructions. Conversely, for opponents of immigration, perspective-taking instructions increased their perception of other's competitiveness compared with participants in the control condition. Taken together, these results underline the importance of taking an individual's views on immigration into account when implementing interventions for conflict resolution in immigration-related issues.

\footnotetext{
${ }^{1}$ Swiss Center for Affective Sciences, University of Geneva, Chemin des Mines 9, 1202 Geneva, Switzerland. ${ }^{2}$ Department of Political Science and International Relations, School of Social Sciences, University of Geneva, Boulevard du Pont d'Arve 40, 1205 Geneva, Switzerland. ${ }^{3}$ Laboratory for Behavioral Neurology and Imaging of Cognition, Departments of Neuroscience and Clinical Neurology, Medical School, University of Geneva, rue Michel Servet 1, 1206 Geneva, Switzerland. ${ }^{4}$ Clinical Psychology and Behavioral Neuroscience, Technische Universität Dresden, Dresden, Germany. ${ }^{5}$ Social Psychology Unit, Faculty of Psychology and Educational Sciences, University of Geneva, Boulevard du Pont d'Arve 40, 1205 Geneva, Switzerland. ${ }^{6}$ Laboratory for the Study of Emotion Elicitation and Expression, Department of Psychology, FPSE, University of Geneva, Boulevard du Pont-d'Arve 40, 1205 Geneva, Switzerland.

凶email: olga.klimecki@unige.ch
} 


\section{Introduction}

$\mathrm{n}$ this study, conducted in Switzerland, we aimed to test how instructions to engage in empathy versus perspective taking affect debates on immigration in proponents and opponents of immigration.

Immigration has become one of the most important subjects of cleavage in contemporary European politics, typically perceived from diametrically opposing standpoints by conservative, authoritarian, and nationalist parties on the one hand and by green, alternative, and liberal globalist parties on the other (Hooghe and Marks, 2018). Since the turn of the millennium, there has been a noticeable movement in Europe towards more restrictive immigration policies (Kofman, 2002). However, immigration policies are fluctuating. A topic currently under debate is the restrictive immigration policies that US president Donald Trump advocates (Romero, 2018) versus the welcoming attitude towards immigration defended by Germany's Chancellor Angela Merkel following the 2015 migration crisis (BaldwinEdwards et al., 2018).

In line with those in other European countries, immigration policies continue to be strongly debated in Switzerland (Riaño and Wastl-Walter, 2006), recently culminating in the popular initiative "against mass immigration". This initiative was launched by the national-conservative Swiss People's Party, which holds restrictive views on immigration (Ruedin, 2013). On February 9,2014 , this initiative was accepted by the Swiss people by a narrow majority of $50.3 \%$ of the votes, illustrating the degree of division in Swiss society when dealing with immigrants. In the current study, we investigated how two previously studied interventions that aimed to promote the understanding of others, namely perspective taking and empathy, affect political discussions on immigration between proponents and opponents of immigration in Switzerland.

Different strategies have been discussed for interventions that can promote conflict resolution. Among the most prominent in interpersonal and intergroup relations are perspective taking and empathy. As described in more detail below, evidence is contradictory on whether these strategies are beneficial (Halperin, 2015; Klimecki, 2019; Ku et al., 2015; Pierce et al., 2013; Underwood and Moore, 1982). One factor that could play a role in interventions related to empathy might be political orientation, as previous research shows that people with leftist political views are more motivated to engage in empathy than are people with rightist political views (Hasson et al., 2018; Porat et al., 2016).

The strategy of perspective taking denotes the act of viewing a situation from the point of view of others, thus helping to identify the other's intentions, needs, reactions, and behaviours (Davis, 1983). Previous research suggests positive relations between trait measures of perspective taking and altruism in interpersonal interactions (Underwood and Moore, 1982). In addition, evidence suggests that trait perspective taking is associated with reduced punishment behaviour (Klimecki et al., 2016), increased liking, perceptions of closeness, approach behaviour, and helping $(\mathrm{Ku}$ et al., 2015). Furthermore, studies in post-conflict settings of Bosnia-Herzegovina point to a positive association between a mixed measure of perspective taking and empathy on the one hand and forgiveness on the other (Brown and Cehajic, 2008, p. 200; Cehajic et al., 2008).

During a negotiation, engaging in perspective taking can improve individual and joint negotiation outcomes (Galinsky et al., 2008), reduce impasses and the need to resort to arbitration (Ku et al., 2015), and help to overcome egocentrism (Chambers and De Dreu, 2014), i.e., reliance on one's own interests and priorities. Moreover, perspective-taking exercises have been shown to decrease discriminatory views, stereotyping, and prejudice towards individuals and groups; improve attitudes towards members of other groups; and increase willingness to engage in intergroup contact (Broockman and Kalla, 2016; Galinsky et al., 2005; Galinsky and Moskowitz, 2000; Ku et al., 2015; Todd et al., 2011; Vescio et al., 2003; Wang et al., 2014). In terms of potential mechanisms, one review (Galinsky et al., 2005) suggests that the beneficial effects of perspective taking are achieved through promoting self-other overlap.

In the context of intergroup conflicts, the use of a perspectivetaking exercise during mediation, compared with mediation without perspective taking, increased the degree to which German participants with restrictive views on immigration liked alleged students of foreign descent who argued in favour of refugees in Germany (Gutenbrunner and Wagner, 2016). This effect was mediated by increased empathy and an increased feeling of being heard (Gutenbrunner and Wagner, 2016).

Despite these beneficial effects of perspective-taking instructions, perspective taking has also been observed to lead to detrimental effects at the level of interpersonal and intergroup interactions ( $\mathrm{Ku}$ et al., 2015). Although most studies do not address this question explicitly, it seems that the detrimental effects of perspective taking on social behaviour can stem from two sources. Firstly, some people may not be motivated to engage in perspective taking. Secondly, engaging in perspective taking itself may deteriorate social relations under specific circumstances (e.g., circumstances related to the characteristics of the perspective taker or of the target).

Perspective taking can in particular backfire if the perspective taker feels threatened (Sassenrath et al., 2016). In line with this notion, perspective-taking instructions were shown to possibly increase egoistic behaviour in competitive interactions (Epley et al., 2006). Similarly, in competitive as opposed to cooperative contexts, perspective-taking instructions promoted egoistic and unethical social behaviour (Pierce et al., 2013). Moreover, a yearlong field study that assessed the impact of perspective taking on intergroup conflict in the Democratic Republic of Congo demonstrated that perspective-taking exercises can increase negative attitudes and reduce helping behaviour towards the outgroup in this society, which is deeply divided by ethnic conflicts (Paluck, 2010). Taken together, these findings suggest that in competitive or conflictual contexts, perspective taking instructions or interventions can promote egoistic and antisocial behaviour.

Notably, the degree to which people glorify their nation or identify with a group has also been shown to modulate whether people are motivated to follow perspective-taking instructions. A study in Australia revealed that only citizens who were low, but not high, in the glorification of their nation (as measured by items such as "Australia is better than other nations in all respects") complied with the instruction to take the perspective of an asylum seeker (Berndsen et al., 2018). Similarly, different effects of perspective taking on intergroup relations were observed for people with a low versus a high identification with their nationality (Zebel et al., 2009). More specifically, a study on Dutch participants revealed that a perspective-taking induction increased feelings of guilt related to past Dutch mistreatments of out-groups in those participants who had a low identification of being Dutch, whereas the perspective-taking instruction decreased feelings of guilt in participants who identified highly as being Dutch (Zebel et al., 2009). As guilt predicted the degree to which participants supported reparations (Zebel et al., 2009), this finding emphasises group identification as an important predictor of how perspective taking will affect intergroup emotions and behaviour. Other research has extended these effects: in participants who highly identified as members of their university, perspective-taking exercises increased the number of negative traits attributed to 
members of another university, while no such effects of perspective taking were found in participants who were low in their identification with their university (Tarrant et al., 2012). Taken together, these studies show that people low in glorification of their nation comply more with the instruction to engage in perspective taking (Berndsen et al., 2018) and that perspective taking has beneficial effects on intergroup relations in participants with a low identification with a group (Zebel et al., 2009), whereas it has negative effects on intergroup relations in people high in identification with their group (Tarrant et al., 2012). More research is needed to determine when and how the lack of motivation to engage in perspective taking (Berndsen et al., 2018), or certain circumstances such as feelings of threat (Sassenrath et al., 2016), explains the detrimental effects of perspective taking on social relations.

In addition to perspective taking, understanding others can also be accomplished by means of empathy, denoting the sharing of the other's emotions while being aware that the other's experience has triggered one's own emotions (de Vignemont and Singer, 2006). Influenced by studies on mirror neurons, investigators have proposed that the empathic understanding of others is accomplished by means of simulating the emotion of the other (Gallese, 2001; Klimecki and Singer, 2013), which suggests that attention to both the other's and one's own emotions plays an important role in empathy.

Similar to perspective taking, empathy has been extensively studied as a precursor of altruism and reduced aggression (de Waal, 2008; Eisenberg and Miller, 1987; Miller and Eisenberg, 1988), as well as a facilitator of interpersonal and intergroup relations (Batson and Ahmad, 2009; Dovidio et al., 2010; Klimecki, 2019; Stephan and Finlay, 1999). However, research has yielded mixed results on the usefulness of empathy as a strategy for improving interpersonal and intergroup relations (Klimecki, 2019). Currently, it is widely recognised that certain forms of empathy, such as compassion-which denotes a positive, otherregarding feeling of concern for another's suffering (Goetz et al., 2010)-are more beneficial for interpersonal and intergroup relations (Dovidio et al., 2010; Klimecki, 2019) than are other forms of empathy, such as empathic distress, which denotes a feeling of being overwhelmed with others' suffering (Davis, 1983) and which can be associated with more aggressive behaviour (Klimecki, 2015; Klimecki et al., 2016).

At the same time, and in parallel with findings in the domain of perspective taking, increasing evidence suggests that political orientation can also modulate empathic responses (Hasson et al., 2018; Pliskin et al., 2014; Porat et al., 2016). More specifically, a series of studies have suggested that people with a leftist, but not a rightist, political orientation change their views on policy support following emotional manipulations (Pliskin et al., 2014), indicating a rigidity of rightists regarding change. Moreover, investigators have observed that leftists are more motivated than rightists to experience empathy for members of other groups (Porat et al., 2016). Another study established that people with a liberal as opposed to a conservative political orientation had increased motivation for empathy, higher levels of experienced empathy, and more pronounced behavioural tendencies oriented towards helping others (Hasson et al., 2018). Finally, it has also been reported that although empathy and intergroup contact can be beneficial on their own, combining empathy induction with an intergroup contact situation between White Canadian participants and Aboriginal Canadians induced derogative reactions towards Aboriginal out-group members in White Canadian participants with higher prejudice (Vorauer and Sasaki, 2009).

These studies suggest that perspective taking and empathy can play an important role in conflict resolution. Furthermore, it is increasingly recognised that the influence of these interventions depends on a series of conditions such as in-group identification (Berndsen et al., 2018; Tarrant et al., 2012; Zebel et al., 2009) and political orientation (Hasson et al., 2018; Pliskin et al., 2014; Porat et al., 2016). Despite these results, it remains unresolved as to whether political orientation affects how instructions for perspective taking and empathy influence dyadic interactions in conflictual issues. The current study aimed to elucidate the degree to which perspective taking and empathy instructions can affect the motivation, emotions, and interpersonal relations of proponents and opponents of immigration. From the literature discussed above, we hypothesised that people who are against immigration would be less open to engage in perspective taking or empathy than would people who are in favour immigration. Similarly, we expected that instructions to empathise or to take the perspective of the other would be more efficient in reducing tensions and promoting interpersonal relations in people who are in favour of immigration than in people who are against it. To test this, we randomly assigned dyads of participants with opposing views on immigration to discuss immigration policies under one of three conditions: perspective-taking instructions, empathy instructions, or no instructions (control).

\section{Methods}

Participants. To investigate the effects of instructions for perspective taking and empathy on discussions between participants holding opposing views on immigration, we randomly allocated 92 participants (46 men, 46 women; age range 18-72 years; $M=27.73$ years; $\mathrm{SD}=9.43$ years) to same-sex dyads in one of three conditions: (i) perspective-taking instructions (30 participants), (ii) empathy instructions (30 participants), or (iii) no instructions (control; 32 participants). Participants were required to be over 18 years old and to speak French fluently. Psychology students were excluded from this experiment because of the risk of being biased. Participants were recruited with flyers posted in dedicated areas of the University of Geneva campus. The flyers advertised a study on "decision making and political opinions" that would last approximately $1 \mathrm{~h}$ and for which remuneration would be $20 \mathrm{CHF}$. Interested individuals were invited to send an e-mail to a dedicated e-mail account. In response to the e-mail, participants received a link to questionnaires (for details, see the Measures subsection) on LimeSurvey (Hamburg, Germany). These questionnaires also included views on immigration. Each dyad was composed of two same-sex participants who met the inclusion criteria: one participant who was in favour of increasing the number of immigrants in Switzerland (hereafter referred to as pro-immigration) and one participant who was against increasing the number of immigrants in Switzerland (hereafter referred to as anti-immigration). Participants were invited to the laboratory by e-mail. All participants indicated that they did not know each other.

As shown in Supplementary Appendix 1, independent $t$-tests revealed that groups of participants were balanced in terms of sex; age; trait empathy, as measured by the French version of the Interpersonal Reactivity Index (IRI) (Davis, 1983; Gilet et al., 2013); alexithymia, as measured by the French version of the 20item Toronto Alexithymia Scale (TAS-20) (Bagby et al., 1994; Loas et al., 2001); and social desirability (Crowne and Marlowe, 1960) (all $t s \leq 1.13$; all $p s \geq 0.23$ ). We also tested whether participants with pro- versus anti-immigration opinions differed in the subscales of the empathy questionnaire (IRI, Davis, 1983). Independent $t$-tests with the between-subject factor opinion on immigration (pro- or anti-immigration) and the scales fantasy, perspective taking, empathic concern, and personal distress as dependent variables revealed that people with different opinions on immigration did not differ significantly on these measures of 
empathy (all $t s \leq 1.48$; all $p s \geq 0.14$ ). Finally, as depicted in Supplementary Appendix 2, participants in the control group spent more time discussing the topic of immigration than did participants in the perspective-taking group and participants in the empathy group (both $p s=0.002$ ); there were no differences between the perspective-taking and empathy groups $(p=0.59)$. All participants provided informed written consent, received 20 CHF per hour for their participation, and were fully debriefed after the experiment. The study was approved by the Research Ethics Committee of the Faculty of Psychology and Educational Sciences at the University of Geneva, Switzerland, and methods were carried out in accordance with the relevant guidelines and regulations.

\begin{abstract}
Measures
Questionnaires. Prior to the study, participants filled in a demographic questionnaire that also assessed their view on immigration. More specifically, they indicated whether immigration to Switzerland and Europe should decrease strongly, decrease moderately, remain the same, increase moderately, or increase strongly. Participants who were in favour of a moderate or strong increase were classified as proponents of immigration (proimmigration), and the other participants were classified as opponents of immigration (anti-immigration). Participants also indicated the frequency with which they discussed the topic of immigration (daily, weekly, monthly, or once a year/never). In addition, they filled in the IRI (Davis, 1983; Gilet et al., 2013) and the TAS-20 (Bagby et al., 1994; Loas et al., 2001) prior to the study and a social desirability questionnaire (Crowne and Marlowe, 1960) at the end of the study.
\end{abstract}

Measures of motivation for perspective taking, empathy, and emotional awareness. Participants' motivation for perspective taking and empathy (including emotional awareness as a component of empathy) were probed with a newly developed questionnaire (Vétois, 2018). In the context of the current study, we analysed the questions explicitly related to motivation for perspective taking ("Have you actively tried to take the perspective of the other?"), empathy ("Have you actively tried to pay attention to the other person's emotions?"), and emotional awareness ("Have you actively tried to pay attention to your emotions?").

Empathic accuracy. To test participants' accuracy in perspective taking and empathy, we used the empathic accuracy procedure (Ickes, 2001). More specifically, participants' discussions on immigration were recorded on videotape, and 5-min excerpts from these recordings were shown to participants on a computer, with the audio being conveyed through headphones. Participants viewed these excerpts privately and at their own pace. They were invited to simultaneously fill in a sheet on which they indicated their thoughts and feelings, along with the relevant time frames. These time frames were then provided to the other participant, along with an indication about whether these time frames were related to a thought or feeling. The other participant in turn inferred the thoughts and/or feelings of the other during these time frames of the 5-min video excerpt. Two independent raters blind to the political orientation or condition of participants assessed the correctness of the inferences on the level of perspective taking and empathy. These data are available for 25 of 30 participants in the empathy condition, 30 of 30 participants in the perspective-taking condition, and 27 of 32 participants in the control condition. Missing data were due to technical problems with the video recording and a missing data sheet for one participant.
Interpersonal closeness. To obtain an implicit measure of interpersonal closeness, we measured whether participants sat closer to each other after the discussion compared with before the discussion. To this end, we took photos of the participants while they were seated on the laboratory sofa, both before and after the discussion on immigration. We have these data for 13 of 15 dyads in the empathy condition, for all 15 dyads in the perspectivetaking condition, and for 15 of 16 dyads in the control condition. Missing data were due to problems with the camera.

Questionnaires related to the discussion. The impact of the instructions was tested through the following questionnaires and qualitative reports that were filled in after the discussion: (i) the Inclusion of Other in the Self Scale (IOS) (Aron et al., 1992) to measure self-other overlap, (ii) the Positive and Negative Affect Schedule (PANAS) (Watson et al., 1988), and (iii) an adapted version of the post-negotiation questionnaire (Schlegel, 2013) in which participants also indicated (i) their satisfaction with their personal result of the discussion, (ii) the degree to which they perceived having won, and (iii) the degree to which they perceived that the other won. The post-negotiation questionnaire contained the following subscales: cooperativeness self, cooperativeness other, competitiveness self, competitiveness other, competence other, and atmosphere (Schlegel, 2013).

Qualitative material. In addition to completing the questionnaires, participants provided a written and open answer to explain whether or not they reached agreement with their counterpart. Two independent raters blind to the political orientation or condition of the participants categorised these answers as (i) rather in conflict, (ii) rather in consensus, or (iii) answers that were not directly relevant to the question. The two independent ratings were then averaged. If both raters gave the same ratings, the labels "rather in agreement", "rather in conflict", or "not known" were attributed to the answers of each participant. If the ratings differed, or if the responses were not relevant, "not known" was used as a category. Moreover, participants were invited to describe whether they used a particular strategy during the discussion. Two independent raters blind to the political orientation or condition of the participants stated whether these strategies were similar to (i) perspective taking, (ii) empathy, or (iii) neither of these two strategies. The two independent ratings were then averaged. If both raters gave the same ratings, the labels "perspective taking" or "empathy" were attributed to the answers of each participant. If the ratings differed or concerned strategies other than empathy and perspective taking, the label "not known" was attributed to these answers. Finally, participants also had the opportunity to provide qualitative reports of their recollection of their own arguments and those of the other. The latter qualitative data were not analysed.

Instructions. Written instructions (in French) were handed to participants prior to their discussion. Participants who were part of the same dyadic discussion always received the same instruction (perspective taking, empathy, or control = no instruction).

The perspective-taking instructions were adapted from the work of Galinsky and colleagues (Galinsky et al., 2008) and stated the following:

In preparing for the discussion and during the discussion, imagine yourself in the shoes of the other person. Try to understand what the other is thinking. After having considered your point of view, try to visualise yourself on the other side of the table, in that role, thinking as the other.

The empathy instruction included paying attention to the other's and to one's own emotions because of the notion that 
empathy is based on simulation mechanisms (Gallese, 2001; Klimecki et al., 2013). It stated the following:

In preparing for the discussion and during the discussion, pay close attention to your own emotions and the emotions of the other person. Try to understand which emotions are present during the discussion. In addition to considering your own emotions, try to be aware of the emotions of the other person.

Participants in the control condition received no instruction in preparation for the discussion in the reception room, but received the same instructions for the task in the experimental room as the participants in both of the other groups.

Procedure. Baseline questionnaires, including the demographic questionnaire, the IRI (Davis, 1983; Gilet et al., 2013) and the TAS-20 (Bagby et al., 1994; Loas et al., 2001) were collected online by using LimeSurvey several days before the study. Participants were scheduled for a laboratory visit if they were eligible to participate. When arriving at the laboratory, participants were greeted and seated on a sofa in the reception room. The experimenter informed the participants about the experiment and handed them a consent form. After they filled in the form, the experimenter took a photo of both participants (allegedly to help the experimenter remember the grouping of the dyads). Participants were then led to the experimental room. Once seated, they were given the "Recommendations for immigration" form that contained ten questions regarding policies related to dealing with immigrants in Switzerland and Europe, with blank spaces for writing their answers in between the questions. Example questions were "Based on what criteria should immigrants be accepted?" and "Which criteria should immigrants fulfil in order to obtain the nationality of the host country?" (the full form can be found in Supplementary Appendix 3). Participants had $20 \mathrm{~min}$ to elaborate their joint written answers to as many questions as possible (the number of agreements reached was counted). During this time, the experimenter left the room and participants' interactions were recoded with two video cameras (one facing each participant). After the discussion, participants filled in the IOS (Aron et al., 1992), the PANAS (Watson et al., 1988), and an adapted version of the postnegotiation questionnaire (Schlegel, 2013); they also provided qualitative written answers to questions that aimed to capture their perception of the negotiation and the extent to which they used perspective taking or empathy by using LimeSurvey. Social desirability (Crowne and Marlowe, 1960) was collected by paper and pencil and with LimeSurvey. In addition, participants completed the empathic accuracy procedure (Ickes, 2001) on 5min video excerpts from their discussion. Participants were then accompanied back to the reception room and invited to sit on the sofa. Pretending an unfortunate loss of the photo taken before the experiment, the experimenter took a second photo of both participants. At the end of the study, participants were thanked, debriefed, and remunerated.

Analyses. Statistical analyses of behavioural data were performed with SPSS Statistics 24 software (IBM; Armonk, NY, USA). A factor analytical approach was used to determine composite scores of the data. Such composite scores represent latent factors that are formed from several related variables. Variables related to the discussion that were measured at the interval level were transformed into scores ranging from 0 to 100 to allow for the computation of composite scores. To determine latent variables related to the outcome measures of the discussion, we conducted an exploratory factor analysis on the following dependent variables: all subscales from the post-negotiation questionnaire (Schlegel, 2013), positive and negative affect (PANAS) (Watson et al., 1988), interpersonal closeness (IOS) (Aron et al., 1992), self-reports on satisfaction, the perception that one won, the perception that the other won, and the number of agreements reached. More specifically, a principal axis factor analysis with oblique rotation (direct oblimin) was conducted on these items.

Baseline differences between groups were assessed with independent $t$-tests. Analyses of variance (ANOVAs) or multivariate analyses of variance (MANOVAs) were conducted to determine whether there were differences between conditions (perspective taking, empathy, and control) and views on immigration (pro- or anti-immigration) by using Wilks' lambda. Pearson correlations were computed to test for the independence of variables between two members of one dyad. Spearman correlations were used to compute the inter-rater reliability for empathic accuracy. Following existing recommendations (Kenny et al., 2006), we tested whether the data between the members of the dyads were independent. If such independence could not be established, i.e., if correlations between the variables for the dyadic members were $p<0.2$ (Kenny et al., 2006), the dyad was used as the unit of analysis and each member of the dyad was treated as a repeated measure. Otherwise, the unit of analysis was the participant.

Chi-square and Fisher's exact tests were used to examine the relationship between condition (perspective taking, empathy, control) and opinion on immigration (pro- versus anti-immigration) with the qualitative report of the negotiation (rather in conflict, rather in agreement, not known) and with the type of technique predominantly used during the negotiation (perspective taking, empathy, not known). The results of the qualitative data analyses can be found in Supplementary Appendix 4.

\section{Results}

Prior to testing whether participants differed in their motivation for perspective taking, empathy, and emotional awareness and in their empathic accuracy (perspective taking and empathy), we conducted Pearson correlations to test whether these dependent variables correlated between the members of dyads. Independence was found for all variables (all $p s \geq 0.22$ ). In light of the independence of these variables for the dyads, we used univariate ANOVAs to test the impact of condition (three levels: perspective taking, empathy, and control) and opinion on immigration (two levels: pro-immigration and anti-immigration) on the motivation of participants for perspective taking, empathy, and emotional awareness (being part of empathy), as well as on participants' empathic accuracy (comprising empathy and perspective taking).

\section{Pro-immigration participants were motivated to follow} empathy or perspective-taking instructions

Motivation for empathy. To test whether condition (perspective taking, empathy, and control) and opinion on immigration (proand anti-immigration) had an impact on the motivation for empathy, we performed a univariate ANOVA. The dependent variable was motivation for empathy (Fig. 1a), and the factors were condition (three levels: perspective taking, empathy, and control) and opinion on immigration (two levels: proimmigration and anti-immigration). This analysis revealed a significant main effect of condition $(F(2,86)=4.67 ; p<0.05)$, no main effect of opinion on immigration $(F(1,86)=2.14 ; p=0.14)$, and an interaction between condition and opinion on immigration $(F(2,86)=3.2 ; p<0.05)$. Follow-up independent $t$-tests that compared pro- and anti-immigration participants in each condition (perspective taking, empathy, and control) revealed higher levels of motivation for empathy in pro- than in anti-immigration participants in the empathy condition $(t(28)=2.94 ; p<0.01)$ and no differences between pro- and anti-immigration participants in the control and perspective-taking conditions (both $t \mathrm{~s} \leq 1.45$; both $p s \geq 0.16$ ). Strengthening the notion that the empathy 
A

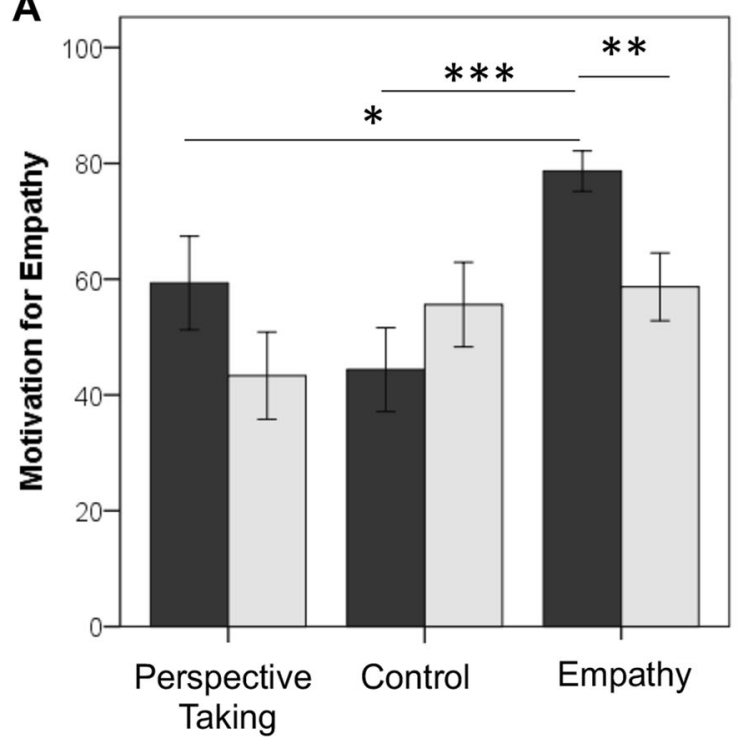

C

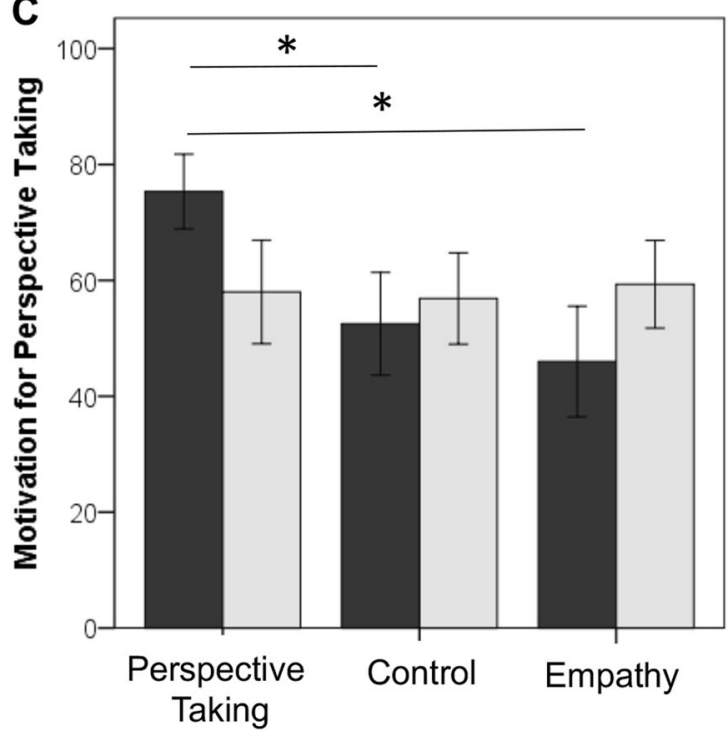

B

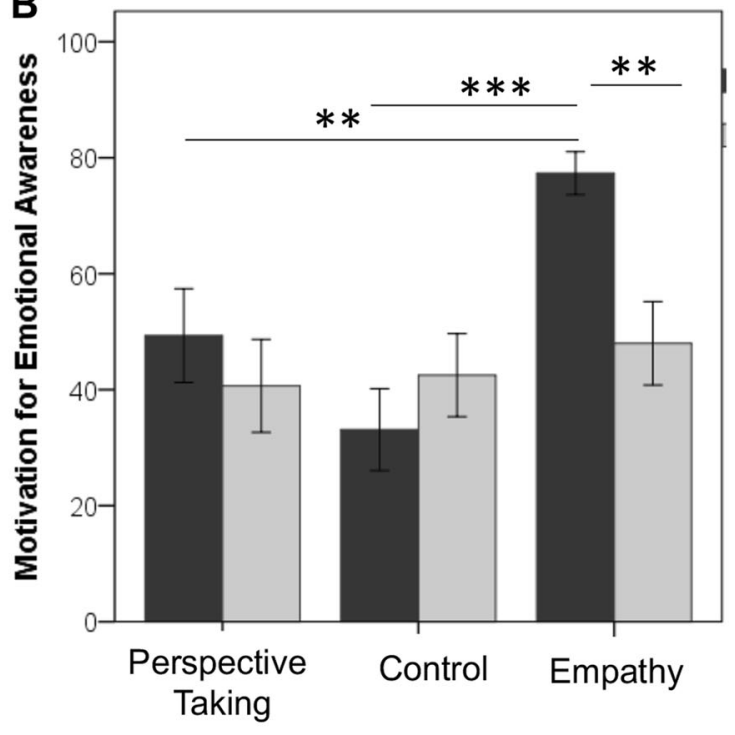

pro immigration anti immigration

Fig. 1 Impact of the empathy or perspective taking instructions on the motivation to engage in empathy, emotional awareness, and perspective taking. Compared with pro-immigration participants in the control group, pro-immigration participants in the empathy group were a more motivated to feel empathy for the other and $\mathbf{b}$ more motivated to pay attention to their own emotions (emotional awareness). Similarly, pro-immigration participants were c more motivated to engage in perspective taking in the perspective-taking group than were pro-immigration participants in the control group.

Furthermore, the motivation to engage in $\mathbf{a}$ empathy and $\mathbf{b}$ emotional awareness was higher in pro-immigration participants than in anti-immigration participants in the empathy group. Error bars depict \pm 1 standard error. ${ }^{\star} p<0.05,{ }^{\star \star} p<0.01,{ }^{\star \star \star} p<0.001$.

instruction affected the motivation of pro-immigration participants, independent $t$-tests that compared the effects of condition (perspective taking, empathy, and control) separately for pro- and anti-immigration participants showed that the empathy condition increased the motivation for empathy in pro-immigration participants when compared with the control condition $(t(29)=4.17$; $p<0.001)$ and when compared with the perspective-taking condition $(t(28)=2.2 ; p<0.05)$, whereas there was no effect of the perspective-taking condition versus the control condition on proimmigration participants $(t(29)=1.38 ; p=0.18)$ and no effect of any of the conditions on anti-immigration participants (all $t \mathrm{~s} \leq$ 1.61 ; all $p s \geq 0.12$ ).

Motivation for emotional awareness. To test whether condition and opinion on immigration had an impact on the motivation for emotional awareness, we performed a univariate ANOVA. The dependent variable was motivation for emotional awareness towards one's own emotions (Fig. 1b); the factors were condition (three levels: perspective taking, empathy, and control) and opinion on immigration (two levels: pro-immigration and antiimmigration). This analysis revealed a significant main effect of condition $(F(2,86)=6.62 ; p<0.01)$, a trend for a main effect of opinion on immigration $(F(1,86)=2.76 ; p=0.1)$, and an interaction between condition and opinion on immigration $(F(2,86)=3.83 ; p<0.05)$. Follow-up independent $t$-tests that compared pro- and anti-immigration participants in each condition (perspective taking, empathy, and control), revealed no difference between participants with different views on immigration in the control condition and the perspective-taking condition (both $t s \leq .93$; both $p s \geq 0.36$ ). However, in the empathy condition, pro-immigration participants reported a higher motivation for emotional awareness than did anti-immigration participants $(t$ 
$(28)=3.63 ; p<0.01)$. Independent $t$-tests that compared the effects of conditions separately for participants who were pro- and anti-immigration showed that although the different conditions had no impact on the motivation for emotional awareness in antiimmigration participants (all $t s \leq .68$; all $p s \geq 0.5$ ), the empathy instruction increased the motivation to pay attention to one's own emotions in pro-immigration participants compared with that in the control group $(t(29)=5.44 ; p<0.001)$ and with that in the perspective-taking group $(t(28)=3.15 ; p<0.01)$. No difference was found between the perspective-taking and the control groups for pro-immigration participants $(t(29)=1.52$; $p=0.14)$.

Motivation for perspective taking. Finally, we tested the impact of condition and opinion on immigration on the motivation for perspective taking by using a univariate ANOVA. The dependent variable was motivation for perspective taking (Fig. 1c), and the factors were condition (three levels: perspective taking, empathy, and control) and opinion on immigration (two levels: proimmigration and anti-immigration). This analysis revealed no significant main effect of condition $(F(2,86)=1.64 ; p=0.2)$, no main effect of opinion on immigration $(F(1,86)=0 ; p=0.99)$, and no interaction between condition and opinion on immigration $(F(2,86)=1.77 ; p<0.18)$. Although this interaction was not significant, we conducted independent $t$-tests to examine whether, in line with previous findings on motivational differences between people of a rightist as opposed to a leftist orientation on indicators of empathy and perspective taking (Berndsen et al., 2018; Hasson et al., 2018; Porat et al., 2016), the same pattern of results as observed for the motivation for emotional awareness and empathy would replicate for the motivation for perspective taking. Indeed, independent $t$-tests that compared the effects of condition (perspective taking, empathy, and control) separately for pro- and anti-immigration participants revealed that proimmigration participants had a higher motivation for perspective taking in the perspective-taking condition as opposed to the control condition $(t(29)=2.06 ; p<0.05)$ and in the perspectivetaking condition as opposed to the emotional awareness condition $(t(28)=2.54 ; p<0.05)$. No other effect of independent $t$ tests, including those comparing pro- and anti-immigration participants in each condition, was significant (all other $t \mathrm{~s} \leq 0.5$; all other $p s \geq 0.62$ ).

Taken together, the results from all three variables related to motivation suggest that pro-immigration participants were motivated to follow the instructions in their condition.

No significant difference in the accuracy of empathy and perspective taking between conditions. To test the degree to which the instructions for empathy and perspective taking influenced pro- and anti-immigration participants in their inference of the other's thoughts and emotions, we used the empathic accuracy procedure (Ickes, 2001). In this procedure, which is based on video excerpts of the conversation in which participants indicate their thoughts and feelings and infer the thoughts and feelings of the other, two raters blind to the condition of participants assessed the degree to which the self-description matched the inferred contents. To assess inter-rater reliability, we computed Spearman correlations between the codings of the two raters on correctly inferred thoughts and correctly inferred emotions. The results revealed good agreement between the two raters on emotions $\left(r_{\mathrm{s}}=0.87\right)$ and thoughts $\left(r_{\mathrm{s}}=0.74\right)$. In light of the independence of this variable between two members of one discussion dyad (as detailed at the beginning of the Results section), we conducted univariate ANOVAs on the percentage of correct thoughts and the percentage of correct emotions, with condition (perspective taking, empathy, and control) and opinion on immigration (pro- or anti-immigration) as factors. No significant effects were found for any of these univariate ANOVAs (all $F s \leq 2.7$, all $p s \geq 0.11$ ), which means that no differences in degree of empathy or perspective taking could be detected between conditions.

No significant difference between conditions on the implicit measure of interpersonal closeness. To test whether the physical distance between participants after the discussion was related to the self-report measure of physical closeness on the IOS (Aron et al., 1992), we computed Pearson correlations between both measures. In contrast to our expectation that explicit and implicit measures of interpersonal closeness would be related, no correlation between these variables was found $(r=0.002, p=0.99)$. This lack of relation between our implicit and explicit measure of interpersonal closeness may have arisen from a ceiling effect, as the sofa we used was perhaps too small, and therefore may have induced small interpersonal distances by default. It may, thus, not be surprising that no effect of condition (perspective taking, empathy, and control condition) was found on changes in physical proximity in a univariate ANOVA with dyad as the unit of analysis $(F(2,40)=0.48, p=0.62)$.

Factor analysis on variables related to conflict. To determine whether there were underlying latent variables for the outcome measures related to the discussion, we conducted an exploratory factor analysis on the following dependent variables: all subscales from the post-negotiation questionnaire (Schlegel, 2013), positive and negative affect (PANAS, Watson et al., 1988), interpersonal closeness (IOS, Aron et al., 1992), self-reports on satisfaction, the perception that one won, the perception that the other won, and the number of agreements reached. More specifically, a principal axis factor analysis with oblique rotation (direct oblimin) was conducted on these items. The sampling adequacy was confirmed by a Kaiser-Meyer-Olkin (KMO) measure of 0.74 and by KMO values for individual items of at least 0.46 (Field, 2013; Hutcheson, 1999). This analysis revealed four factors with eigenvalues above Kaiser's criterion of 1 . Altogether, these four factors explained $63.96 \%$ of the variance. The factor loadings after rotation are shown in Supplementary Appendix 5. According to the items loading on the factors, Factor 1 was interpreted as Cooperativeness, Factor 2 as Competitiveness and Positive and Negative Emotions, Factor 3 as Success of the Negotiation, and Factor 4 as Agreement.

Perspective taking reduced levels of competitiveness and positive and negative emotions in pro-immigration participants. In the next step, the composite scores corresponding to each factor were computed by multiplying each participant's value on the item with the factor loading of this item on the relevant factor. Prior to this computation, all items had been rescaled to a scale from 0 to 100 . To assess the effects of opinion on immigration and condition on the four composite scores as dependent variables, we conducted a repeated-measures MANOVA with dyad as the level of analysis, opinion on immigration (pro- or anti-immigration) as repeated measures within a dyad, and condition (perspective taking, empathy, and control) as a between-subject factor. Dyad was chosen as a level of analysis due to the potential non-independence of the variables of each member of the dyad on composite scores Agreement, Success, Competitiveness, and Emotion (all $p<0.2$ ). For the composite score Cooperativeness, the correlation between the values of both members of the dyad was $p=0.81$. No main effect of opinion on immigration $(F(8,80)=0.77 ; p=0.63)$ or condition $(F(4,40)=$ $1.27 ; p=0.3)$ was observed, but there was a significant interaction 
of opinion on immigration and condition $(F(8,80)=2.12$; $p<0.05)$. Follow-up univariate ANOVAs revealed that there was a significant interaction between opinion on immigration and condition on Competitiveness and Positive and Negative Emotions $(p<0.05)$ and a trend for an interaction on Agreement $(p=0.1)$, but there was no interaction for the variables Cooperativeness and Success of the Negotiation (both $p s \geq 0.53$ ). As depicted in Fig. 2, follow-up pairwise $t$-tests with the repeated measure opinion on immigration (pro- or anti-immigration) were separately conducted for each of the conditions (perspective taking, empathy, and control) on the dependent variables Competitiveness and Positive and Negative Emotions. These tests revealed that in the perspective-taking condition, proimmigration participants had lower levels of Competitiveness and Positive and Negative Emotions than did anti-immigration participants $(t(14)=2.83 ; p<0.05)$. Conversely, there was a trend in the control condition for pro-immigration participants to report higher levels of Competitiveness and Positive and Negative Emotions than reported by the anti-immigration participants, but it did not reach significance $(t(15)=2.02 ; p=0.06)$. Finally, no significant differences between pro- and anti-immigration participants were found in the empathy condition $(t(14)=0.37$; $p=0.72$ ). Independent $t$-tests that compared the effect of condition (perspective taking, empathy, and control) separately for pro- and anti-immigration participants revealed that perspective taking decreased Competitiveness and Positive and Negative Emotions in pro-immigration participants compared to participants in the control condition $(t(29)=2.06 ; p<0.05)$, whereas a trend in the opposite direction was observed for anti-immigration participants $(t(29)=1.85 ; p=0.07)$, indicating that perspective taking reduced levels of Competitiveness and Positive and Negative Emotions in pro-immigration participants. No other differences between conditions were found (all other $t s \leq 1.46$; all other $p s \geq 0.16$ ).

To test which components of the composite score drove this effect, we followed this result up with a repeated-measures MANOVA with dyad as the level of analysis, opinion on immigration (pro- or anti-immigration) as a repeated measure within a dyad, condition (perspective taking, empathy, and control) as a between-subject factor, and the four components of

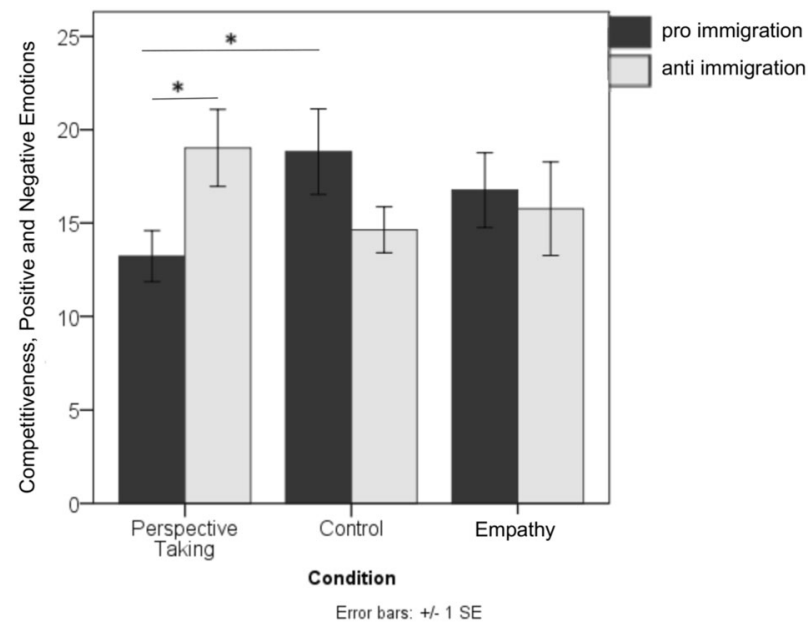

Fig. 2 Pro-immigration participants in the perspective-taking group had lower scores of competitiveness and emotions than did pro-immigration participants in the control group or anti-immigration participants in the perspective-taking group. The graph depicts mean scores of the composite score Competitiveness and Positive and Negative Emotions for the conditions perspective taking, control, and empathy. Error bars depict \pm 1 standard error. ${ }^{*} p<0.05$. the composite scores (competitiveness self, competitiveness other, positive affect, negative affect) as dependent variables. In line with the results on the composite score, there was no main effect of condition $(F(8,80)=0.86 ; p=0.55)$ or opinion $(F(4,40)=0.28$; $p=0.89)$, but there was a significant interaction of condition and opinion $(F(8,80)=2.8 ; p=0.009)$. Univariate tests revealed that this interaction was significant for the dependent variables positive affect, negative affect, and competitiveness other (all ps $<0.05)$, but not for competitiveness self $(p=0.19)$.

Follow-up pairwise $t$-tests with the factor opinion on immigration (pro- or anti-immigration) were conducted for each of the conditions (perspective taking, empathy, and control) on the dependent variables positive affect, negative affect, and competitiveness of the other. Furthermore, independent $t$-tests that compared the effect of condition (perspective taking, empathy, and control) separately for pro- and anti-immigration participants were conducted on the dependent variables positive affect, negative affect, and competitiveness of the other.

Empathy and perspective-taking instructions affect emotions in pro-immigration participants. To test whether positive affect differed for participants with opposing views on immigration (pro- or anti-immigration), we conducted pairwise $t$-tests with the repeated-measure factor opinion on immigration (pro- or anti-immigration) for each of the conditions (perspective taking, empathy, and control) separately (Fig. 3a). These tests revealed that there was no significant difference in positive affect between pro- and anti-immigration participants in the control condition $(t$ $(15)=0.46 ; p=0.65)$. However, in the empathy condition, proimmigration participants had more positive emotions than did anti-immigration participants $(t(14)=2.17 ; p<0.05)$. Conversely, in the perspective-taking condition, pro-immigration participants tended to feel less positive emotions than did anti-immigration participants $(t(14)=2.07 ; p=0.06)$. Independent $t$-tests that compared the effect of condition (perspective taking, empathy, and control) separately for pro- and anti-immigration participants revealed that pro-immigration participants had lower levels of positive affect in the perspective-taking condition than in the control condition $(t(29)=2.79 ; p<0.01)$. Furthermore, proimmigration participants had higher levels of positive affect in the empathy condition than they did in the perspective-taking condition $(t(28)=2.39 ; p<0.05)$. No other effects were observed (all other $t s \leq 1.55$; all other $p s \geq 0.13$ ).

To test whether negative affect differed for participants with opposing views on immigration (pro- or anti-immigration), we conducted pairwise $t$-tests with the repeated-measure factor opinion on immigration (pro- or anti-immigration) for each of the conditions (perspective taking, empathy, and control) separately (Fig. 3b). These tests showed that there were no differences between pro- and anti-immigration participants in the control or empathy condition (both $t s \leq 1.66$; both $p s \geq 0.12$ ). However, pro-immigration participants had less negative affect than anti-immigration participants did in the perspective-taking condition $(t(14)=2.4 ; p<0.05)$. Independent sample $t$-tests that compared the effect of condition (perspective taking, empathy, and control) separately for pro- and anti-immigration participants showed that pro-immigration participants had less negative affect in the perspective-taking condition than they did in the control and empathy conditions (both $t \mathrm{~s} \geq 2.25$; both $p s<0.05$ ). No other effect was significant (all other $t s \leq 1.55$; all other ps $\geq 0.13)$.

Opponents of immigration perceive the other as being more competitive under perspective-taking instructions. To test whether opinion on immigration (pro- or anti-immigration) had 

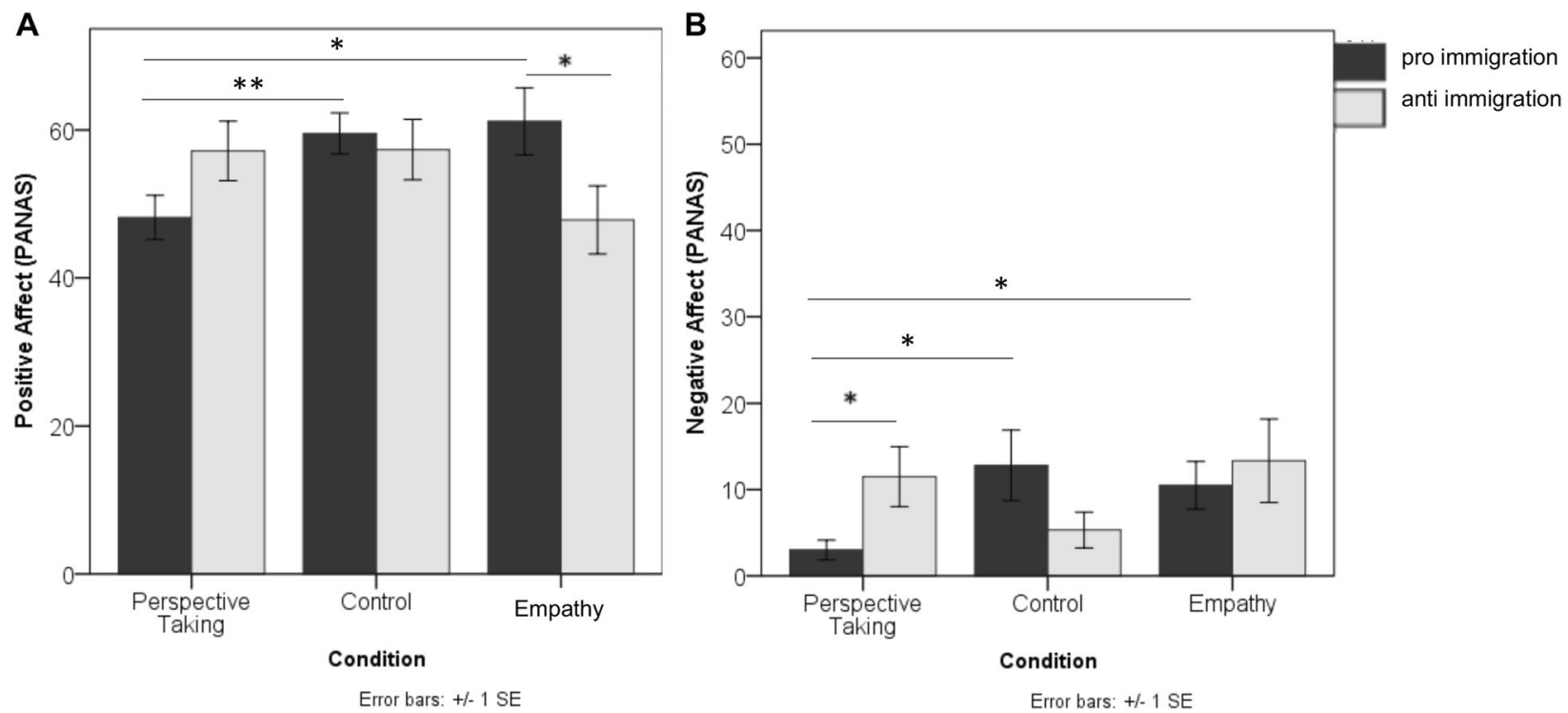

Fig. 3 Differences in positive and negative affect between proponents and opponents of immigration across groups. a Positive affect was lower in proimmigration participants in the perspective-taking group than in pro-immigration participants in the control or the empathy group. Moreover, in the empathy group, pro-immigration participants had higher scores of positive affect than did anti-immigration participants. b Negative affect was lower in proimmigration participants in the perspective-taking condition than it was in pro-immigration participants in the control or empathy condition. The graph depicts mean scores of $\mathbf{a}$ positive affect and $\mathbf{b}$ negative affect. Error bars depict \pm 1 standard error. ${ }^{\star} p<0.05,{ }^{\star *} p<0.01$.

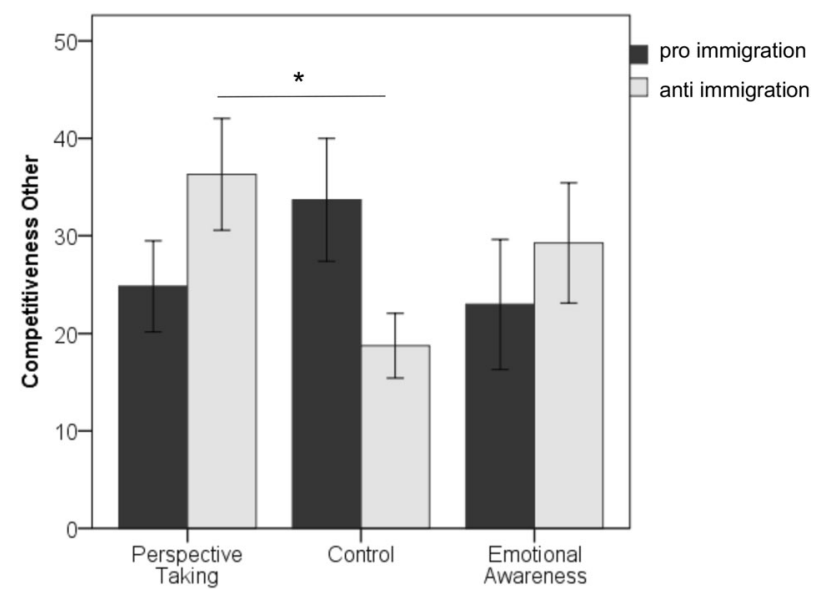

Fig. 4 Anti-immigration participants in the perspective group had a higher perception of the other's competitiveness than did antiimmigration participants in the control group. The graph depicts mean scores of competitiveness of the other. Error bars depict \pm 1 standard error. ${ }^{*} p<0.05$.

an effect on the perceived competitiveness of the other (Fig. 4), we conducted pairwise $t$-tests with the repeated-measure factor opinion on immigration (pro- or anti-immigration) for each of the conditions (perspective taking, empathy, and control) separately. These tests indicated that in the control condition, proimmigration participants tended to report more competitiveness of the other than did anti-immigration participants $(t(15)=2.12$; $p=0.05$ ), whereas no differences in the perspective-taking or empathy conditions were present (both $t s \leq 1.49$; both $p s \geq 0.16$ ). Independent sample $t$-tests that compared the effect of condition (perspective taking, empathy, and control) separately for pro- and anti-immigration participants revealed that anti-immigration participants had increased ratings of the other's competitiveness in the perspective-taking condition compared with those in the control condition $(t(29)=2.69 ; p<0.05)$. No other effects were observed (both $t s \leq 1.53$; both $p s \geq 0.14$ ).

\section{Discussion}

The current study investigated whether the impact of instructions for empathy and perspective taking prior to discussions of immigration issues would differ for proponents versus opponents of immigration. To this end, dyads of same-sex participants with opposing views on immigration were randomly assigned to discuss immigration policies under three conditions: perspectivetaking instructions, empathy instructions, or no instructions (control condition). The present results extend previous findings that rightists are more resistant to experimental manipulations than leftists (Pliskin et al., 2014) and that people high in glorification of their nation are more reluctant to engage in perspective taking towards asylum seekers than are people low in glorification of their nation (Berndsen et al., 2018), by revealing that participants in favour of immigration were motivated to follow both the perspective-taking and empathy instructions. These motivational effects were mirrored on the level of emotions, but not on the level of actual empathy or perspective taking. More specifically, perspective taking decreased the level of negative and positive emotions in participants in favour of immigration. Interestingly, the present results also suggest that perspective-taking instructions can aggravate conflicts under certain conditions, as participants with restrictive views on immigration had a higher perception of the other's competitiveness in the perspective-taking condition than they did in the control condition.

Previous studies have found that people with a leftist as opposed to a rightist political orientation have increased motivations for empathy, as well as higher levels of empathy and a higher motivation for prosocial behaviour (Hasson et al., 2018; Porat et al., 2016). The current results extend this notion by showing that the motivation to engage in empathy when instructed to do so is increased in proponents of immigration. A 
similar pattern was observed for perspective taking: here, we showed that instructions for perspective taking were met with the motivation to follow the instruction in the pro-immigration participants. Together with the previous observation that people who are high in the glorification of their nation comply less with the instruction to adopt the perspective taking of an asylum seeker than do people who are low in the glorification of their nation (Berndsen et al., 2018), this result suggests that people with a more liberal view on immigration are motivated to adopt the perspective of others when instructed to do so.

Paralleling these motivational findings, perspective taking attenuated emotions of the pro-immigration participants in the present study. In line with previous meta-analytic findings showing that perspective taking (towards oneself) decreases the intensity of positive and negative emotions (Wallace-Hadrill and Kamboj, 2016; Webb et al., 2012), pro-immigration participants reported lower positive and negative emotions in the perspective-taking condition than they did in the control condition in our study. Interestingly, pro-immigration participants also reported more positive emotions than did anti-immigration participants in the empathy condition, suggesting that empathy selectively promotes positive emotions in proponents of immigration. As an increase in positive emotions has been postulated to be one of the mechanisms through which empathy inductions improve interpersonal and intergroup relations (Klimecki, 2019), future research that explores these links in more depth is warranted.

Notably, our study suggests that perspective-taking instructions can even have a detrimental effect on interpersonal relations, as opponents of immigration reported higher levels of the other's competitiveness in the perspective-taking condition than they did in the control condition. This effect was present even though there was no significant effect of the instruction on the motivation for perspective taking in opponents of immigration. These results may be interpreted in two ways because the competitiveness of the other is a self-report variable that refers to the discussion partner's behaviour. One may, thus, interpret it either as an actual increase in the other's competitive behaviour, or as an increase in the perception of the other's competitive behaviour. The current experiment does not enable us to delineate whether one of these interpretations is more relevant than the other, or whether both interpretations are equally true.

This result is in line with previous findings that perspective taking can have negative effects on intergroup relations in high identifiers (Tarrant et al., 2012) and with the finding that perspective taking has beneficial effects for intergroup relations in people with a low identification with their group (Zebel et al., 2009). Nonetheless, our finding contrasts with existing evidence (Gutenbrunner and Wagner, 2016) that during a conflict over immigration, participants with a restrictive view on immigration reported increased empathy, interpersonal liking, and a feeling of being heard by the counterpart following a perspective-taking induction with a mediator. These differing results may stem from the facilitation by a mediator (Gutenbrunner and Wagner, 2016), which may have decreased the feeling of threat to the self in participants with restrictive views on immigration, which otherwise might have been related to adverse effects of perspective taking on interpersonal relations (Gutenbrunner and Wagner, 2016). In light of recent evidence for the beneficial effects of mediation on conflict resolution (Rafi et al., 2020), future studies could explore the role of mediators and the role of threat perception in more depth.

In summary, our finding suggests that perspective taking increased either the competitiveness of pro-immigration participants, or the perception of competitiveness in anti-immigration participants, or both. What is common to all these interpretations is that the result adds to the existing evidence ( $\mathrm{Ku}$ et al., 2015; Sassenrath et al., 2016) that perspective taking is not always beneficial for social relations. Extending previous findings that showed that perspective taking may increase egoistic behaviour in competitive contexts (Epley et al., 2006; Pierce et al., 2013) or exacerbate intergroup intolerance in conflict situations (Paluck, 2010), the present finding underlines that views on immigration may modulate the effectiveness of perspective-taking instructions on social relations. Potential processes that may play a role in this context are feelings of threat that are induced if the counterpart is perceived as too different from the self, or if adopting the perspective of another highlights possible negative evaluations of the self by others, especially in negative interdependent contexts such as conflicts (Sassenrath et al., 2016). In previous research (Berndsen et al., 2018), the instruction to take the perspective of an asylum seeker increased feelings of threat, prejudice, and the active efforts to refrain from perspective taking in participants high in glorification of their nation.

Although our study showed that views on immigration modulate how people engage in perspective taking and empathy, its limitations and those of experiments of this type in general might be addressed in future studies. First, the present results raise the question of the conditions under which opponents of immigration would engage in perspective taking or empathy. In line with the current observation that opponents of immigration were not motivated to engage in any of the interventions, future studies could try to influence the motivation of the participants, for instance, by increasing positive affect or affiliation, which have been proposed to decrease motivation to avoid empathy (Zaki, 2014). To achieve this, it might be interesting to implement targeted training of positive emotions that strengthen the affiliation with others, even beyond one's group (Klimecki, 2019). Indeed, previous studies have shown that targeted training can increase positive emotions (Klimecki et al., 2013) and prosocial behaviour (Leiberg et al., 2011).

Second, our experiment was based on instructions for perspective taking (Galinsky et al., 2008) and empathy. Although some previous instruction-based studies that aimed to promote interpersonal understanding through perspective taking or empathy have proven to be effective in changing interpersonal and intergroup relations (Klimecki, 2019), it would be interesting to test the impact of more extensive exercises (Galinsky and Moskowitz, 2000) or of longer-term interventions in the future. More extensive studies may, thus, assess the degree to which views on immigration modulate training effects of perspective taking or empathy on motivation, emotions, and social relations. Moreover, future studies could test the degree to which conditions such as political orientation are related to perceived threat (Sassenrath et al., 2016) and whether interventions such as mediation can help to reduce threat perception.

Another limitation is that the current study did not distinguish between different forms of empathy, such as compassion, which denotes a feeling of care for suffering others (Goetz et al., 2010), and empathic (or personal) distress, which denotes a feeling of being overwhelmed by the suffering of others (Davis, 1983). As previous studies have shown opposing effects of compassion and empathic distress on interpersonal and intergroup relations (Klimecki, 2019), which may be due to the previously observed link between positive affect and prosocial behaviour (Isen et al., 1978), it would be interesting to investigate their role in more depth.

In addition, the discussion on immigration between two strangers of opposing political views in the current experiment represents a relatively mild form of disagreement. Future studies could test the degree to which results differ in the context of violent or intractable intergroup conflicts. Here, it may also be of interest to explicitly study the role of group-based emotions (Smith and Mackie, 2015) and whether the degree of group identification plays a role (Berndsen et al., 2018; Tarrant et al., 2012; Zebel et al., 2009). 
Moreover, the question of endogeneity still remains to be resolved in future research. As participants cannot be randomly assigned to be pro or anti-immigration, it might be that certain endogeneous factors, such as education or socio-economic status differ between these groups. While there was no age difference between pro and anti-immigration participants in the present sample, we did not assess education or socio-economic status. As education (Weakliem, 2002) or socio-economic status (Šram, 2008) can be related to political opinions, more work is needed to investigate the issue of endogeneity in more depth.

Finally, although laboratory experiments such as the present one allow manipulation of certain factors in order to test their impact on human behaviour, they are limited by the artificial conditions in which the tested interactions occur. To gain a more complete understanding of human behaviour and of social movements, it is important to complement the present study with field research, as well as with historical and anthropological studies.

The current study results suggest that opinion on immigration can modulate responses to perspective taking and empathy inductions in the context of conflicts over immigration in Switzerland by showing that (i) proponents of immigration were motivated to engage in perspective taking and empathy, (ii) proponents of immigration showed a decrease in the level of negative and positive emotions after perspective taking instructions, and (iii) perspective-taking instructions should be used with caution, as they increased the perception of other's competitiveness in opponents of immigration.

In line with the general observation that people with an authoritarian view are more rigid in their beliefs (Schultz and Searleman, 2002), the present findings suggest that in order to be successful, policies that aim to improve relations between opponents and proponents of immigration should consider that interventions can have a different impact depending on the target group and their motivation. In other words, policymakers and people who design interventions that aim to reach opponents of immigration will have to find alternative strategies to mere instructions for perspective taking or empathy. Most likely, indirect strategies of emotion regulation (e.g., reappraisal), which work by changing core appraisals (i.e., underlying evaluations) related to the emotion that one would like to change might work better than trying to change the emotional response itself, as these indirect interventions circumvent the issue of motivation (Halperin et al., 2011). Future studies are needed to test interventions based on indirect emotion regulation in opponents and proponents of immigration.

\section{Data availability}

Anonymized data will be made available upon request.

Received: 11 September 2019; Accepted: 30 July 2020;

Published online: 10 September 2020

\section{References}

Aron A, Aron EN, Smollan D (1992) Inclusion of Other in the Self Scale and the structure of interpersonal closeness. J Pers Soc Psychol 63:596-612. https:// doi.org/10.1037/0022-3514.63.4.596

Bagby RM, Taylor GJ, Parker JDA (1994) The twenty-item Toronto Alexithymia scale-II. Convergent, discriminant, and concurrent validity. J Psychosom Res 38:33-40. https://doi.org/10.1016/0022-3999(94)90006-X

Baldwin-Edwards M, Blitz BK, Crawley H (2018) The politics of evidence-based policy in Europe's 'migration crisis. J Ethn Migr Stud 45:2139-1155. https:// doi.org/10.1080/1369183X.2018.1468307

Batson CD, Ahmad NY (2009) Using empathy to improve intergroup attitudes and relations. Soc Issues Policy Rev 3:141-177. https://doi.org/10.1111/j.17512409.2009.01013.x
Berndsen M, Thomas EF, Pedersen A (2018) Resisting perspective-taking: glorification of the national group elicits non-compliance with perspective-taking instructions. J Exp Soc Psychol 79:126-137. https://doi.org/10.1016/j. jesp.2018.07.007

Broockman D, Kalla J (2016) Durably reducing transphobia: a field experiment on door-to-door canvassing. Science 352:220-224. https://doi.org/10.1126/ science.aad 9713

Brown R, Cehajic S (2008) Dealing with the past and facing the future: mediators of the effects of collective guilt and shame in Bosnia and Herzegovina. Eur J Soc Psychol 38:669-684. https://doi.org/10.1002/ejsp.466

Cehajic S, Brown R, Castano E (2008) Forgive and forget? Antecedents and consequences of intergroup forgiveness in Bosnia and Herzegovina. Polit Psychol 29:351-367. https://doi.org/10.1111/j.1467-9221.2008.00634.x

Chambers JR, De Dreu CKW (2014) Egocentrism drives misunderstanding in conflict and negotiation. J Exp Soc Psychol 51:15-26. https://doi.org/10.1016/ j.jesp.2013.11.001

Crowne DP, Marlowe D (1960) A new scale of social desirability independent of psychopathology. J Consult Psychol 24:349-354. https://doi.org/10.1037/ h0047358

Davis MH (1983) Measuring individual differences in empathy: evidence for a multidimensional approach. J Pers Soc Psychol 44:113-126. https://doi.org/ 10.1037/0022-3514.44.1.113

de Vignemont F, Singer T (2006) The empathic brain: how, when and why? Trends Cogn Sci 10:435-441. https://doi.org/10.1016/j.tics.2006.08.008

de Waal FBM (2008) Putting the altruism back into altruism: the evolution of empathy. Annu Rev Psychol 59:279-300. https://doi.org/10.1146/annurev. psych.59.103006.093625

Dovidio JF, Johnson JD, Gaertner SL, Pearson AR, Saguy T, Ashburn-Nardo L (2010) Empathy and intergroup relations. In: Shaver PR, Mikulincer M (eds) Prosocial motives, emotions, and behavior: the better angels of our nature. American Psychological Association, Washington, DC, pp, 393-408

Eisenberg N, Miller PA (1987) The relation of empathy to prosocial and related behaviors. Psychol Bull 101:91-119. https://doi.org/10.1037/0033-2909.101.1.91

Epley N, Caruso E, Bazerman MH (2006) When perspective taking increases taking: reactive egoism in social interaction. J Pers Soc Psychol 91:872-889. https://doi.org/10.1037/0022-3514.91.5.872

Field A (2013) Discovering statistics using IBM SPSS statistics. SAGE, London

Galinsky AD, Maddux WW, Gilin D, White JB (2005) Perspective-taking and selfother overlap: fostering social bonds and facilitating social coordination. Group Process Intergroup Relat 8:109-124. https://doi.org/10.1177/ 1368430205051060

Galinsky AD, Maddux WW, Gilin D, White JB (2008) Why it pays to get inside the head of your opponent: the differential effects of perspective taking and empathy in negotiations. Psycho. Sci 19:378-384. https://doi.org/10.1111/ j.1467-9280.2008.02096.x

Galinsky AD, Moskowitz GB (2000) Perspective-taking: decreasing stereotype expression, stereotype accessibility, and in-group favoritism. J Pers Soc Psychol 78:708-724. https://doi.org/10.1037//0022-3514.78.4.708

Gallese V (2001) The "shared manifold" hypothesis: from mirror neurons to empathy. In: Thompson EE (ed.) Between ourselves: second-person issues in the study of consciousness. Imprint Academic, Charlottesville, VA, pp. 33-50

Gilet AL, Mella N, Studer J, Grühn D, Labouvie-Vief G (2013) Assessing dispositional empathy in adults: a French validation of the Interpersonal Reactivity Index (IRI). Can J Behav Sci Can Sci Comport 45:42-48. https:// doi.org/10.1037/a0030425

Goetz JL, Keltner D, Simon-Thomas E (2010) Compassion: an evolutionary analysis and empirical review. Psychol Bull 136:351-374. https://doi.org/10.1037/ a 0018807

Gutenbrunner L, Wagner U (2016) Perspective-taking techniques in the mediation of intergroup conflict. Peace Confl J Peace Psychol 22:298-305. https://doi. org/10.1037/pac0000184

Halperin E (2015) Emotions in conflict. Routledge, London

Halperin E, Russell AG, Trzesniewski KH, Gross JJ, Dweck CS (2011) Promoting the Middle East peace process by changing beliefs about group malleability. Science 333:1767-1769. https://doi.org/10.1126/science.1202925

Hasson Y, Tamir M, Brahms KS, Cohrs JC, Halperin E (2018) Are liberals and conservatives equally motivated to feel empathy toward others? Per Soc Psychol Bull 44:1449-1459. https://doi.org/10.1177/0146167218769867

Hooghe L, Marks G (2018) Cleavage theory meets Europe's crises: Lipset, Rokkan, and the transnational cleavage. J Eur Public Policy 25:109-135. https://doi. org/10.1080/13501763.2017.1310279

Hutcheson G (1999) The multivariate social scientist. SAGE, London

Ickes W (2001) Measuring empathic accuracy. In: Bernieri FJ, Hall JA (eds) Interpersonal sensitivity: theory and measurement. Lawrence Erlbaum Associates, Mahwah, NJ, pp. 219-241

Isen AM, Shalker TE, Clark M, Karp L (1978) Affect, accessibility of material in memory, and behavior: a cognitive loop? J Pers Soc Psychol 36:1-12. https:// doi.org/10.1037//0022-3514.36.1.1 
Kenny DA, Kashy DA, Cook WL (2006) Dyadic data analysis. Guilford Press, New York

Klimecki O, Singer T (2013) Empathy from the perspective of social neuroscience. In: Armony J, Vuilleumier P (eds) The Cambridge handbook of human affective neuroscience. Cambridge University Press, Cambridge, pp. 533-550

Klimecki OM (2015) The plasticity of social emotions. Soc Neurosci 10:466-473. https://doi.org/10.1080/17470919.2015.1087427

Klimecki OM (2019) The role of empathy and compassion in conflict resolution. Emot Rev 11:310-325. https://doi.org/10.1177/1754073919838609

Klimecki OM, Leiberg S, Lamm C, Singer T (2013) Functional neural plasticity and associated changes in positive affect after compassion training. Cere Cortex 23:1552-1561. https://doi.org/10.1093/cercor/bhs142

Klimecki OM, Vuilleumier P, Sander D (2016) The impact of emotions and empathy-related traits on punishment behavior: introduction and validation of the inequality game. PLoS ONE 11:e0151028. https://doi.org/10.1371/ journal.pone. 0151028

Kofman E (2002) Contemporary European migrations, civic stratification and citizenship. Polit Geogr 21:1035-1054. https://doi.org/10.1016/S0962-6298(02)00085-9

Ku G, Wang CS, Galinsky AD (2015) The promise and perversity of perspectivetaking in organizations. Res Organ Behav 35:79-102. https://doi.org/10.1016/ j.riob. 2015.07 .003

Leiberg S, Klimecki O, Singer T (2011) Short-term compassion training increases prosocial behavior in a newly developed prosocial game. PLoS ONE 6:e17798. https://doi.org/10.1371/journal.pone.0017798

Loas G, Corcos M, Stephan P, Pellet J, Bizouard P, Venisse JL, Perez-Diaz F, Guelfi JD, Jeammet P (2001) Factorial structure of the 20-item Toronto Alexithymia Scale: confirmatory factorial analyses in nonclinical and clinical samples. J Psychosom Res 50:255-261. https://doi.org/10.1016/S0022-3999(01)00197-0

Miller PA, Eisenberg N (1988) The relation of empathy to aggressive and externalizing/antisocial behavior. Psychol Bull 103:324-344. https://doi.org/ 10.1037/0033-2909.103.3.324

Paluck EL (2010) Is it better not to talk? Group polarization, extended contact, and perspective taking in Eastern Democratic Republic of Congo. Pers Soc Psychol Bull 36:1170-1185. https://doi.org/10.1177/0146167210379868

Pierce JR, Kilduff GJ, Galinsky AD, Sivanathan N (2013) From glue to gasoline: how competition turns perspective takers unethical. Psychol Sci 24:1986-1994. https://doi.org/10.1177/0956797613482144

Pliskin R, Bar-Tal D, Sheppes G, Halperin E (2014) Are leftists more emotiondriven than rightists? The interactive influence of ideology and emotions on support for policies. Pers Soc Psychol Bull 40:1681-1697. https://doi.org/ $10.1177 / 0146167214554589$

Porat R, Halperin E, Tamir M (2016) What we want is what we get: group-based emotional preferences and conflict resolution. J Pers Soc Psychol 110:167-190. https://doi.org/10.1037/pspa0000043

Rafi H, Bogacz F, Sander D, Klimecki O (2020) Impact of couple conflict and mediation on how romantic partnersare seen: An fMRI study. Cortex 130:302-317. https://doi.org/10.1016/j.cortex.2020.04.036

Riaño Y, Wastl-Walter D (2006) Immigration policies, state discourses on foreigners, and the politics of identity in Switzerland. Environ Plan Econ Space 38:1693-1713. https://doi.org/10.1068/a37411

Romero M (2018) Trump's immigration attacks, in brief. Contexts 17:34-41. https://doi.org/10.1177/1536504218766549

Ruedin D (2013) Obtaining party positions on immigration in Switzerland: comparing different methods. Swiss Polit Sci Rev 19:84-105. https://doi.org/ $10.1111 /$ spsr.12018

Sassenrath C, Hodges SD, Pfattheicher S (2016) It's all about the self: when perspective taking backfires. Curr Dir Psychol Sci 25:405-410. https://doi.org/ $10.1177 / 0963721416659253$

Schlegel K (2013) Improving the measurement of emotion recognition ability. Dissertation, University of Geneva

Schultz PW, Searleman A (2002) Rigidity of thought and behavior: 100 years of research. Genet Soc Gen Psychol Monogr 128:165-207

Smith ER, Mackie DM (2015) Dynamics of group-based emotions: insights from intergroup emotions theory. Emot Rev 7:349-354. https://doi.org/10.1177/ 1754073915590614

Šram Z (2008) Ideological Structuring of Socio-Economic Orientations. Revija za socijalnu politiku 15:209-223

Stephan WG, Finlay K (1999) The role of empathy in improving intergroup relations. J Soc Issues 55:729-743. https://doi.org/10.1111/0022-4537.00144

Tarrant M, Calitri R, Weston D (2012) Social identification structures the effects of perspective taking. Psychol Sci 23:973-978. https://doi.org/10.1177/ 0956797612441221

Todd AR, Bodenhausen GV, Richeson JA, Galinsky AD (2011) Perspective taking combats automatic expressions of racial bias. J Pers Soc Psychol 100:1027-1042. https://doi.org/10.1037/a0022308
Underwood B, Moore B (1982) Perspective-taking and altruism. Psychol Bull 91:143-173. https://doi.org/10.1037/0033-2909.91.1.143

Vescio TK, Sechrist GB, Paolucci MP (2003) Perspective taking and prejudice reduction: the mediational role of empathy arousal and situational attributions. Eur J Soc Psychol 33:455-472. https://doi.org/10.1002/ejsp.163

Vétois M (2018) The Motivated Empathy and Perspective Taking Questionnaire: preliminary validation from a negotiation context. Student Report, University of Geneva

Vorauer JD, Sasaki SJ (2009) Helpful only in the abstract?: ironic effects of empathy in intergroup interaction. Psychol Sci 20:191-197. https://doi.org/10.1111/ j.1467-9280.2009.02265.x

Wallace-Hadrill SMA, Kamboj SK (2016) The impact of perspective change as a cognitive reappraisal strategy on affect: a systematic review. Front Psychol 7. https://doi.org/10.3389/fpsyg.2016.01715

Wang CS, Kenneth T, Ku G, Galinsky AD (2014) Perspective-taking increases willingness to engage in intergroup contact. PLoS ONE 9:e85681. https://doi. org/10.1371/journal.pone.0085681

Watson D, Clark L, Tellegen A (1988) Development and validation of brief measures of positive and negative affect: the PANAS scales. J Pers Soc Psychol 54:1063-1070. https://doi.org/10.1037//0022-3514.54.6.1063

Weakliem DL (2002) The Effects of Education on Political Opinions: An International Study. Int J Public Opin Res 14:141-157. https://doi.org/10.1093/ ijpor/14.2.141

Webb TL, Miles E, Sheeran P (2012) Dealing with feeling: a meta-analysis of the effectiveness of strategies derived from the process model of emotion regulation. Psychol Bull 138:775-808. https://doi.org/10.1037/a0027600

Zaki J (2014) Empathy: a motivated account. Psychol Bull 140:1608-1647. https:// doi.org/10.1037/a0037679

Zebel S, Doosje B, Spears R (2009) How perspective-taking helps and hinders group-based guilt as a function of group identification. Group Process Intergroup Relat 12:61-78. https://doi.org/10.1177/1368430208098777

\section{Acknowledgements}

We thank Milica Garic for her help in the study. This work was supported by the National Centre of Competence in Research (NCCR) for the Affective Sciences, financed by a grant from the Swiss National Science Foundation (51NF40-104897), hosted by the University of Geneva.

\section{Author contributions}

$\mathrm{OK}, \mathrm{MV}$, and DS designed the experiment, MV carried out the experiment, OK analysed the data, OK, MV, and DS wrote the paper, all authors approved of the final version of the paper

\section{Competing interests}

The authors declare no competing interests.

\section{Additional information}

Supplementary information is available for this paper at https://doi.org/10.1057/s41599 020-00581-0.

Correspondence and requests for materials should be addressed to O.M.K.

Reprints and permission information is available at http://www.nature.com/reprints

Publisher's note Springer Nature remains neutral with regard to jurisdictional claims in published maps and institutional affiliations.

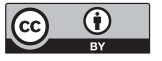

Open Access This article is licensed under a Creative Commons Attribution 4.0 International License, which permits use, sharing, adaptation, distribution and reproduction in any medium or format, as long as you give appropriate credit to the original author(s) and the source, provide a link to the Creative Commons license, and indicate if changes were made. The images or other third party material in this article are included in the article's Creative Commons license, unless indicated otherwise in a credit line to the material. If material is not included in the article's Creative Commons license and your intended use is not permitted by statutory regulation or exceeds the permitted use, you will need to obtain permission directly from the copyright holder. To view a copy of this license, visit http://creativecommons.org/ licenses/by/4.0/.

(C) The Author(s) 2020 